\title{
Ikonografia witraży Wiktora Ostrzołka w gdańskim kościele Mariackim (1977-1980)
}

\author{
https://doi.org/10.26881/porta.2021.20.09
}

Słowa kluczowe: sztuka sakralna, witraż, Milenium Chrztu Polski

Keywords: sacred art, stained glass, Millennium of the Baptism of Poland

W końcu lat siedemdziesiątych XX w. gdański kościół Mariacki wyposażono w dwa znacznych rozmiarów witraże, $\mathrm{z}$ których jeden wypełnił okno tzw. kaplicy Kapłańskiej, drugi zaś - wielkie okno zamykające prezbiterium świątyni. Autorem koncepcji obu przeszkleń był Wiktor Ostrzołek, czołowy projektant witraży w powojennej Polsce ${ }^{1}$. Związany z Katowicami twórca już kilka lat wcześniej dał się poznać w Trójmieście w związku z projektem witraży i dekoracji sgraffitowej dla kościoła franciszkanów w gdańskim Nowym Porcie ${ }^{2}$ oraz witraży dla kościoła garnizonowego pw. św. Jerzego w Sopocie ${ }^{3}$. Wobec braku stosownych źródel ${ }^{4}$ trudno ustalić, czy te wcześniejsze prace, zrealizowane na terenie gdańskiej diecezji, wpłynęły na powierzenie Ostrzołkowi prestiżowego zlecenia w jednej z największych i najwspanialszych świątyń w Polsce, która niewiele wcześniej została podniesiona do godności bazyliki mniejszej bullą Pawła VI, wystawioną 20 listopada 1965 r., a zatem w przededniu rozpoczęcia w polskim Kościele uroczystości Milenium Chrztu Polski. Jakkolwiek projekty witraży powstały dopiero kilkanaście lat później, to jednak ich program ikonograficzny wyraźnie odwołuje się właśnie do wątków milenijnych, ukazując tysiącletnią obecność Kościoła w historii Polski. Oba monumentalne dzieła Ostrzołka można więc uznać za swoiste podsumowanie, a biorąc pod uwagę ich skalę i wizualną

1 Wiktor Ostrzołek (ur. 1934) zaprojektował witraże dla blisko stu wnętrz sakralnych, głównie w Polsce, ale także we Włoszech, Niemczech, Austrii, Holandii i Francji. Na temat twórczości artysty zob. przede wszystkim: Henryk Pyka, Witraże Wiktora Ostrzołka. Pięćdziesiąt lat twórczości, Katowice 2006.

$2 \quad$ Ibidem, s. 71 oraz kat. nr 17.

3 Ibidem, kat. nr 27.

4 Nie udało się, jak dotąd, odnaleźć dokumentacji związanej z zamówieniem i realizacją witraży, co nie znaczy, że takowa nie istnieje, należy bowiem zaznaczyć, że archiwalia dotyczące powojennych zleceń artystycznych w kościele Mariackim wciąż nie zostały w pełni uporządkowane. Za informację w tym zakresie dziękuję p. Annie Kriegseisen, byłej pełnomocniczce proboszcza Bazyliki Mariackiej w Gdańsku do spraw ochrony zabytków. 
wyrazistość - wręcz za zwieńczenie okołomilenijnej aktywności włodarzy gdańskiej świątyni w zakresie wyposażania jej zarówno w okolicznościowe, jak i trwałe dzieła sztuki ${ }^{5}$.

Prezentację projektów Ostrzołka warto poprzedzić krótkim omówieniem prac, które pojawiły się w kościele Mariackim w związku z obchodami milenijnymi, a zwłaszcza ich ikonografii, którą w znacznej mierze można uznać za zapowiedź ikonografii późniejszych witraży. W czasie kulminacji gdańskich obchodów, w maju 1966 r., prezbiterium świątyni (il. 1) ozdobiono zaprojektowaną przez Krystynę Jacobson monumentalną tkaniną, na której naprzemiennie ukazano dwa motywy heraldyczne: polskiego orła w różnych historycznych redakcjach oraz herb Gdańska w wersji z trzymaczami w postaci lwów. Na tym tle umieszczono obraz autorstwa Barbary Massalskiej Chrzest Polski ${ }^{6}$ (il. 2). Z kolei na filarze przy tzw. kaplicy Kapłańskiej zawieszono sztandar, również autorstwa Jacobson ${ }^{7}, \mathrm{w}$ formie obozowego pasiaka z numerami księży-więźniów ${ }^{8}$. Dekoracja ta odnosiła się więc bezpośrednio do powstałego nieco wcześniej wystroju kaplicy Kapłańskiej, ufundowanej w roku 1965 w miejscu dawnej kaplicy Bractwa Kapłańskiego Najświętszej Marii Panny ${ }^{9}$. Posługując się ascetyczną, nowoczesną formą, upamiętniono $\mathrm{w}$ niej polskich duchownych, zamordowanych

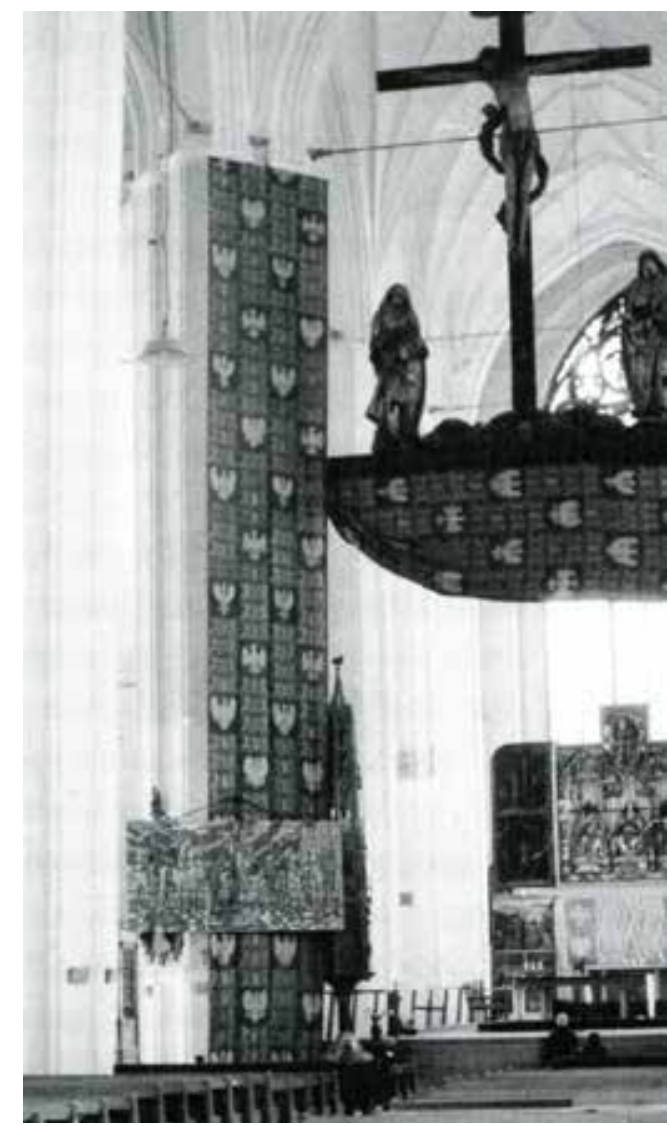

Il. 1. Prezbiterium kościoła Mariackiego w Gdańsku podczas obchodów milenijnych, maj 1966, fot. ze zbiorów prywatnych, repr. za: Jacek Bielak, Nowoczesność w strefie sacrum...

5 Proces ten zaprezentował Jacek Bielak w artykule Nowoczesność w strefie sacrum. Dekoracje milenijne w kościele Mariackim w Gdańsku [w:] Nowoczesność w sztuce i w myśli o sztuce na Pomorzu od XIX do XXI wieku, red. Jacek Bielak, Józef Tarnowski, Gdańsk 2015, s. 219-251. Bielak skupia się na pracach powstałych bezpośrednio w związku z obchodami milenijnymi, nie uwzględnia więc powstałych później witraży Wiktora Ostrzołka.

6 Ibidem, s. 235-236. Zob. też Katarzyna Lincer, Malarstwo monumentalne w twórczości Barbary Massalskiej na terenie Trójmiasta, Gdańsk 2014 (praca licencjacka napisana w Instytucie Historii Sztuki UG pod kierunkiem Jacka Friedricha).

7 Bielak, Nowoczesność w strefie sacrum..., s. 249.

8 Wpis w kronice parafialnej z 29 maja 1966 roku, za: ibidem, s. 251.

9 Stanisław Bogdanowicz, Dzieła sztuki sakralnej Bazyliki Mariackiej w Gdańsku, Gdańsk 1990, s. 219. 


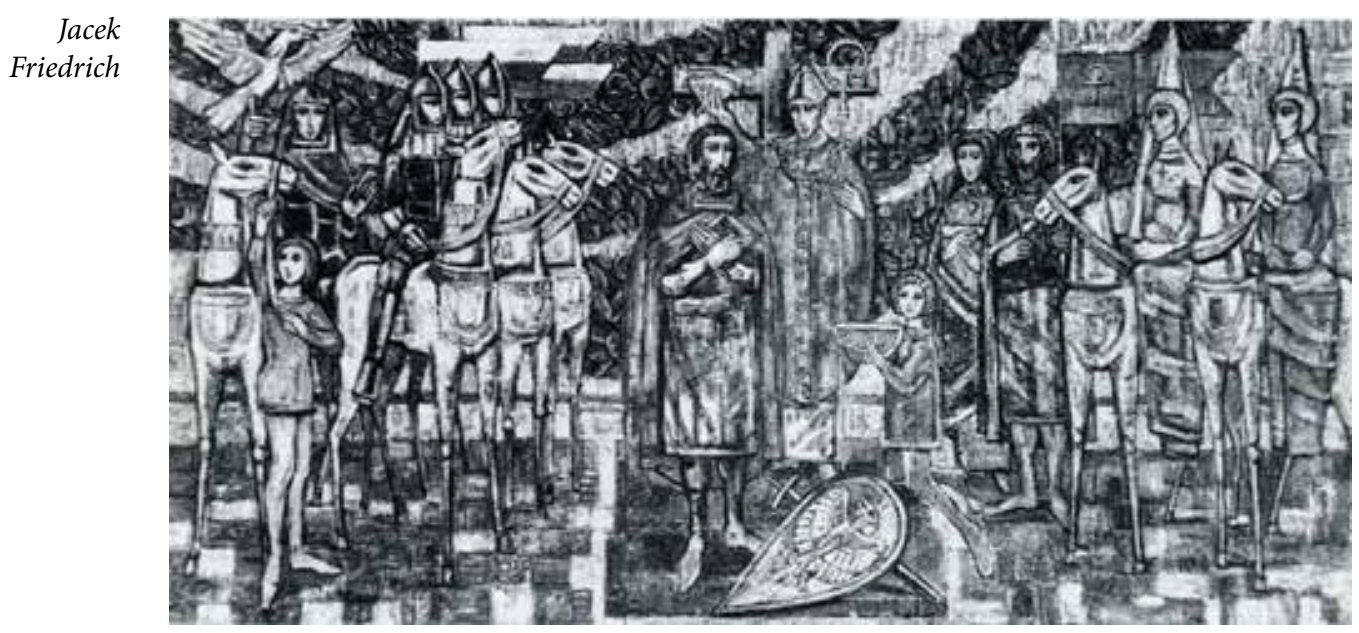

Il. 2. Barbara Massalska, Chrzest Polski, 1966, repr. za: Katarzyna Lincer, Malarstwo monumentalne w twórczości Barbary Massalskiej...

podczas wojny. Najistotniejszym elementem tej artystycznej kreacji stała się figura Chrystusa Frasobliwego autorstwa Janiny Stefanowicz-Schmidt (il. 3) ${ }^{10}$. Jak widać, milenijna dekoracja kościoła Mariackiego wyraźnie wiązała losy Polski z dziedzictwem chrześcijańskim, co dodatkowo podkreślono prezentowaną w tym samym czasie we wnętrzu świątyni wystawą edukacyjną o wymownym tytule „Zasługi Kościoła dla kultury w Polsce" ${ }^{\text {. }}$. W dekoracji kaplicy Kapłańskiej położono natomiast nacisk na męczeńską śmierć polskich kapłanów, a ów martyrologiczny przekaz miał znaleźć kontynuację w późniejszym o dekadę witrażu Ostrzołka.

Kompozycje witrażowe zaprojektowane przez artystę dla gdańskiego kościoła na zamówienie ówczesnego proboszcza ks. Józefa Zator-Przytockiego

10 Ibidem, s. 249. Szerzej na temat powojennych losów i wystroju tzw. kaplicy Kapłańskiej zob. Jacek Bielak, Von der „Priester-Kapelle” bis zur „Kapelle der Seeleute”. Die maritime Identität Danzigs am Beispiel der Innenausstattung der Danziger Marienkirche [w:] Die Maritime Stadt - Hafenstädte an der Ostsee vom Mittelalter bis in die Gegenwart. Beiträge der 21. Tagung des Arbeitskreises deutscher und polnischer Kunsthistoriker und Denkmalpfleger in Gdańsk 18-21 September 2013 / Miasto nad morzem - miasta portowe nad Bałtykiem od średniowiecza do wspótczesności. Materiały 21. konferencji Grupy Roboczej Polskich i Niemieckich Historyków Sztuki i Konserwatorów Zabytków w Gdańsku 18-21 września 2013, red. Tomasz Torbus, Katarzyna Anna Wojtczak, Warszawa 2017, s. 474-486.

11 Treści zaprezentowane na tej ekspozycji wzbudziły czujność cenzury, która domagała się zgłoszenia wystawy do kontroli, zob. Bielak, Nowoczesność w strefie sacrum..., s. 235. Na temat reakcji reżimu komunistycznego na obchody milenijne w diecezji gdańskiej zob. Igor Hałagida, Pomorze Gdańskie [w:] Milenium czy Tysiąclecie, red. Bartłomiej Noszczak [b.d., b.m.], s. 237-251; Daniel Gucewicz, Próba sit? Rok 1966 w Gdańsku. Milenium kontra Tysiąclecie, Gdańsk 2014. W skali ogólnopolskiej okołomilenijny konflikt pomiędzy państwem i Kościołem omawia m.in. Bartłomiej Noszczak, „Sacrum” czy „profanum”? - spór o istotę obchodów Milenium polskiego (1949-1966), Warszawa 2002, zwłaszcza s. 179-247. 


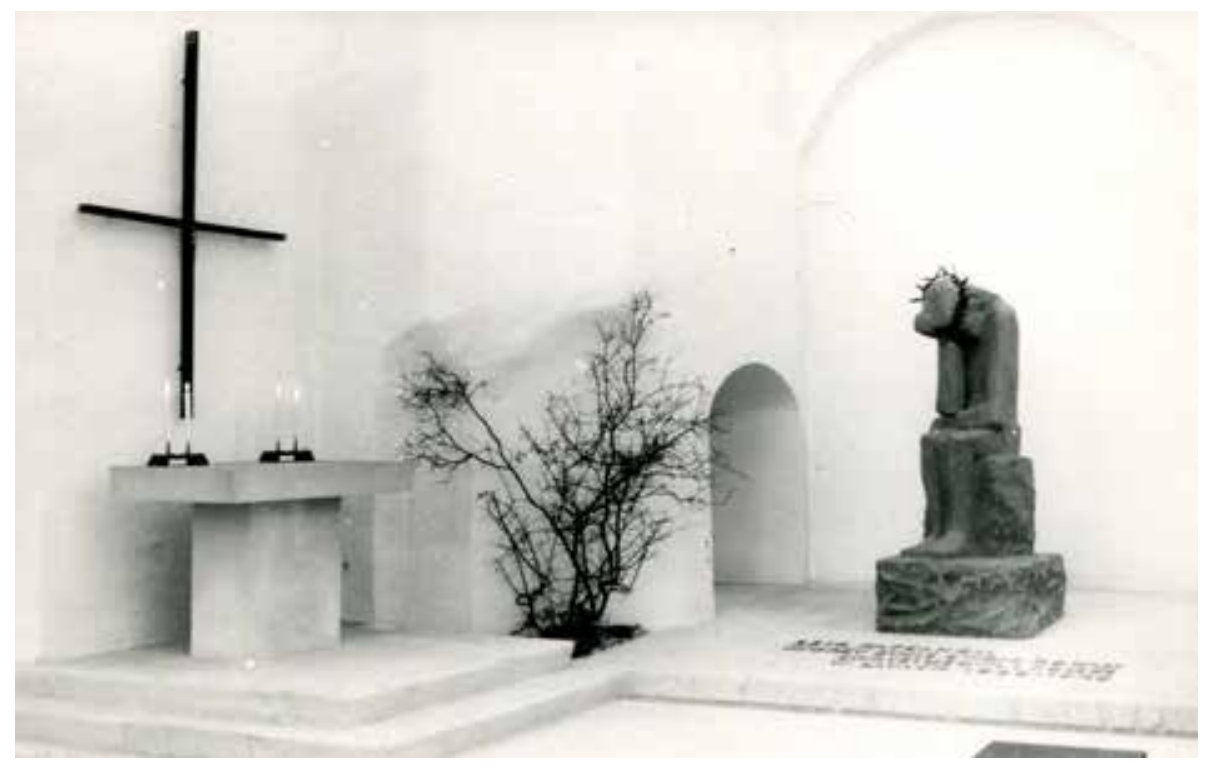

Ikonografia

witraży

Wiktora

Ostrzołka...

Il. 3. Kaplica Kapłańska w kościele Mariackim w Gdańsku z rzeźbą Chrystusa Frasobliwego Janiny Stefanowicz-Schmidt, 1965, fot. anonimowa ze zbiorów autora

w pierwotnym zamyśle miały stanowić - jak pisano w ówczesnej prasie - jedynie początek „monumentalnej pracy obliczonej na wiele lat” ${ }^{12}$, tj. ozdobienia witrażami całej świątyni. Nie wiadomo, jakie treści przekazywałby cały zamierzony zespól, można jednak przyjrzeć się jego dwóm ukończonym elementom i na ich podstawie rekonstruować sposób myślenia zleceniodawcy, którego nagła śmierć zatrzymała realizację niebywale ambitnego zamierzenia ${ }^{13}$.

Gdańskie witraże zostały zaprojektowane przez Ostrzołka w jego katowickiej pracowni ${ }^{14}$, a wykonane w Krakowskim Zakładzie Witraży „Renowacja”. Jako pierwsze powstało przeszklenie okna w kaplicy Kapłańskiej, o powierzchni ponad $52 \mathrm{~m}^{2}$, zamontowane pomiędzy 26 września a 3 października $1978 \mathrm{r}^{16}$

12 M. Guzowska, Witraże z Krakowa dla Gdańska. Jedyna w kraju wytwórnia zasypana zamówieniami, „Express Wieczorny” 1978, nr 2, cyt. za: Pyka, Witraże Wiktora Ostrzołka..., s. 75.

13 Ks. płk Józef Zator-Przytocki zmarł podczas odprawiania nabożeństwa w kościele Mariackim 26 listopada 1978 r. W czasie wojny był kapelanem Armii Krajowej, po wojnie był więziony i szykanowany przez władze komunistyczne. Jako proboszcz parafii Mariackiej (od 1958 r.) odegrał kluczową rolę w przygotowaniu gdańskiej świątyni do obchodów milenijnych, zob. Piotr Szubarczyk, Ksiądz płk dr Józef Zator-Przytocki „Czeremosz” (21 I 1912 - 26 XI 1978), „Nasz Dziennik” 2006, nr 281, http://mtrojnar.rzeszow.opoka.org.pl/ksieza_niezlomni/jozef_ zator-przytocki [dostęp: 28.02.2021].

14 Mówił o tym sam artysta: „W tej pracowni powstał witraż do bazyliki Mariackiej w Gdańsku, który ma 22 metry wysokości...”, cyt. za: Mirosław Rzepka, Myślenie światłem, http:// www.opoka.org.pl/biblioteka/I/IS/witraze.html [dostęp: 28.02.2021].

15 Pyka, Witraże Wiktora Ostrzołka..., kat. nr 36.

16 Ibidem; Bogdanowicz, Dzieła sztuki sakralnej..., s. 220. 


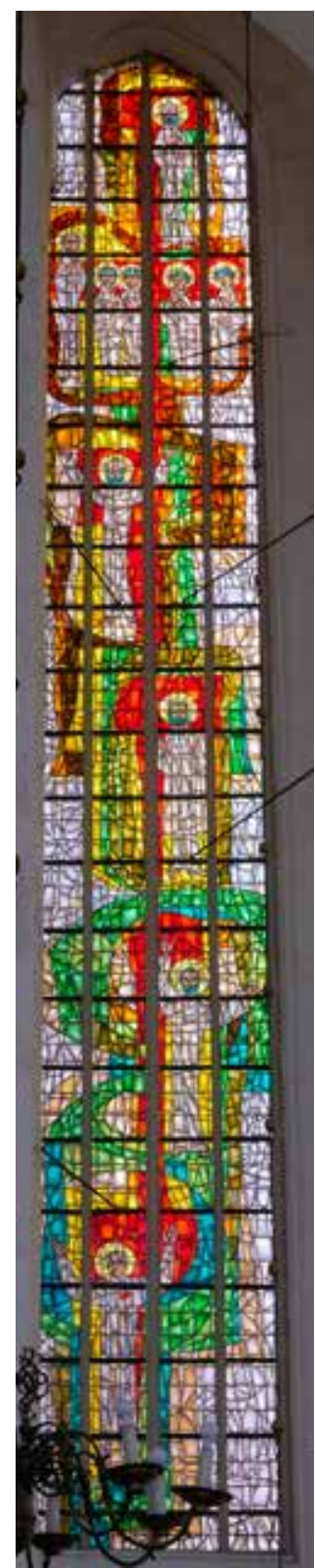

Il. 4. Witraż w oknie kaplicy Kapłańskiej kościoła Mariackiego w Gdańsku, proj. Wiktor Ostrzołek, 1978, fot. Dariusz Kula Images
Następnie wykonano wielki - o powierzchni ponad $130 \mathrm{~m}^{2}$ - witraż w oknie wschodniej ściany świątyni, którego montaż zakończono 21 października 1980 r. ${ }^{17}$, już po śmierci zleceniodawcy.

Jak wspomniano, program ikonograficzny ${ }^{18}$ pierwszego $\mathrm{z}$ witraży bezpośrednio odwołuje się do wymowy aranżacji kaplicy z 1965 r., w której upamiętniono męczeńską śmierć polskich kapłanów w czasie drugiej wojny światowej. Tematyka witrażu nie ograniczała się jednak do czasów najnowszych, a przeciwnie - ukazywała kapłanów męczenników związanych z dziejami Polski od samych jej początków (il. 4). W układzie wertykalnym ukazano więc tutaj św. Wojciecha, Pięciu Braci Męczenników (il. 5), św. Stanisława, św. Jana Sarkandra (il. 6), św. Andrzeja Bobolę oraz św. Maksymiliana Kolbego (wówczas, gdy witraż powstawał - jeszcze błogosławionego $)^{19}$, przy czym św. Wojciech zajmuje pozycję u góry kompozycji, rozpoczynając chronologicznie uporządkowaną narrację, a ojciec Kolbe - pozycję u dołu, narrację tę zamykając (il. 7). Takie usytuowanie postaci współczesnego męczennika przestrzennie przybliża ją do wcześniejszego pomnika księży pomordowanych podczas wojny, a tym samym włącza Maksymiliana Kolbego do ich grona. Formalną, a zarazem ikonograficzną dominantę przedstawienia na witrażu stanowi ciągła czerwona linia rozszerzająca się przy poszczególnych postaciach i w ten sposób tworząca ich tło. Jest to oczywista wizualna metafora krwi męczeńskiej ${ }^{20}$, wszakże można się chyba dopatrzyć w tej wyrazistej formie jeszcze jednej warstwy znaczeniowej - ciągłość owej linii łączącej św. Wojciecha ze św. Maksymilianem (a więc także początki państwa polskiego ze współczesnością) ukazuje równocześnie nieprzerwaną obecność Kościoła w polskich dziejach.

Tę więź w sposób jeszcze bardziej jednoznaczny wyraża program ikonograficzny drugiego $z$ witraży, zdobiącego wielkie okno prezbiterium (il. 8). Jest on także o wiele ściślej związany z wątkami dominującymi w kościelnych obchodach milenijnych. Główny motyw monumentalnego przedstawienia stanowi tu postać stojącej Marii z szeroko rozwartymi ramionami obleczonymi

17 Ibidem, s. 280.

18 W tym miejscu zajmuję się jedynie stroną ikonograficzną obu witraży, pomijam zaś kwestie artystyczne, takie jak choćby miejsce gdańskich realizacji w dorobku twórczym ich autora. Na ten temat zob. Pyka, Witraże Wiktora Ostrzołka..., s. 74-76.

19 Jednoznaczną identyfikację świętych umożliwiają zawarte w kompozycji inskrypcje.

${ }_{20}$ Ten aspekt trafnie wskazał już Pyka, Witraże Wiktora Ostrzołka..., kat. nr 36. 
w ciemnobłękitny płaszcz, w który wkomponowano dziewięć odrębnych przedstawień. Za nią ukazana została postać Chrystusa o rozkrzyżowanych ramionach, $\mathrm{z}$ uwidocznionymi śladami Męki. W maswerku wieńczącym okno umieszczono wyobrażenie Ducha Świętego pod postacią gołębicy i towarzyszące mu języki ogniste, które identyfikują całe przedstawienie jako Zesłanie Ducha Świętego ${ }^{21}$. Z perspektywy niniejszych rozważań szczególnie ciekawe są środkowe i dolne partie witraża, a więc samo wyobrażenie Marii oraz przedstawienia ujęte jej płaszczem. Przede wszystkim zwraca tu uwagę ogólne podobieństwo do tradycyjnego ujęcia Mater Misericordiae, przy czym opiekuńczym płaszczem Marii nie są objęci - jak w prototypie - mniej lub bardziej liczni wierni, ale odrębne, niekiedy dość złożone grupy obrazowe. Jest ich w sumie dziewięć i można je podzielić na dwie kategorie: część z nich ma charakter ogólnoeklezjologiczny, część zaś wiąże się już ściśle z dziejami Kościoła w Polsce.

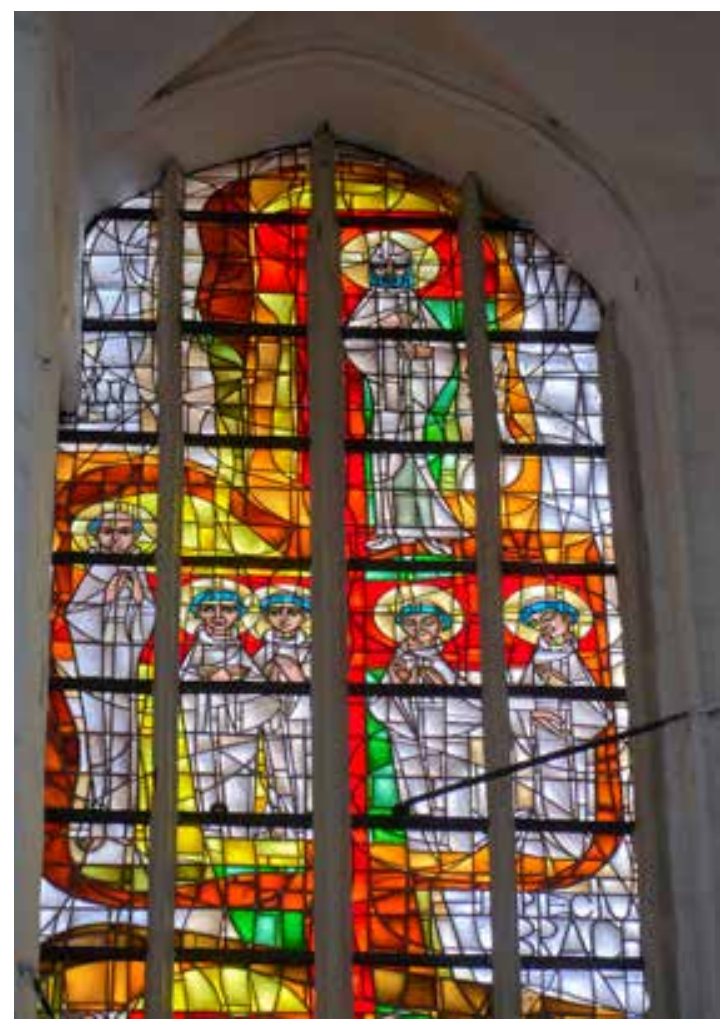

Il. 5. Św. Wojciech i Pięciu Męczenników, fragment witraża w kaplicy Kapłańskiej kościoła Mariackiego w Gdańsku, 1978, proj. Wiktor Ostrzołek, fot. Dariusz Kula Images Wedle ks. Stanisława Bogdanowicza, następcy ks. Zator-Przytockiego na stanowisku proboszcza, pierwszą grupę stanowią starotestamentowe figury Kościoła - owczarnia (pasterz z owcami), mieszkanie Boga (widok rzymskiej Bazyliki św. Piotra, murowanego domu i prostej chaty), uprawna rola (pług na roli, drzewo), górne Jeruzalem (stylizowany widok Jerozolimy), Oblubienica Baranka (postać kobieca w wianku i baranek), droga (wędrowiec z kijem) ${ }^{22}$.

21 Być może jest to spostrzeżenie ryzykowne, ale wyobrażenie gołębicy z potężnymi, wysoko uniesionymi skrzydłami jest tu dość odległe od tradycyjnych ujęć tego motywu, przez co przypomina nieco heraldycznego polskiego Orła Białego. W świetle całego programu ikonograficznego omawianego witraża, w którym wątek Kościoła w Polsce zajmuje eksponowane miejsce, ukazanie symbolu państwowego byłoby nawet uzasadnione, jednak $\mathrm{z}$ teologicznego punktu widzenia trudno sobie chyba wyobrazić świadomy wybór tego rodzaju rozwiązania, ocierającego się o świętokradztwo. Zapewne więc tę nietypową formę należy tłumaczyć chęcią harmonijnego wpisania motywu w zastany przez projektanta rysunek maswerku.

22 Bogdanowicz, Dzieła sztuki sakralnej..., s. 280. 


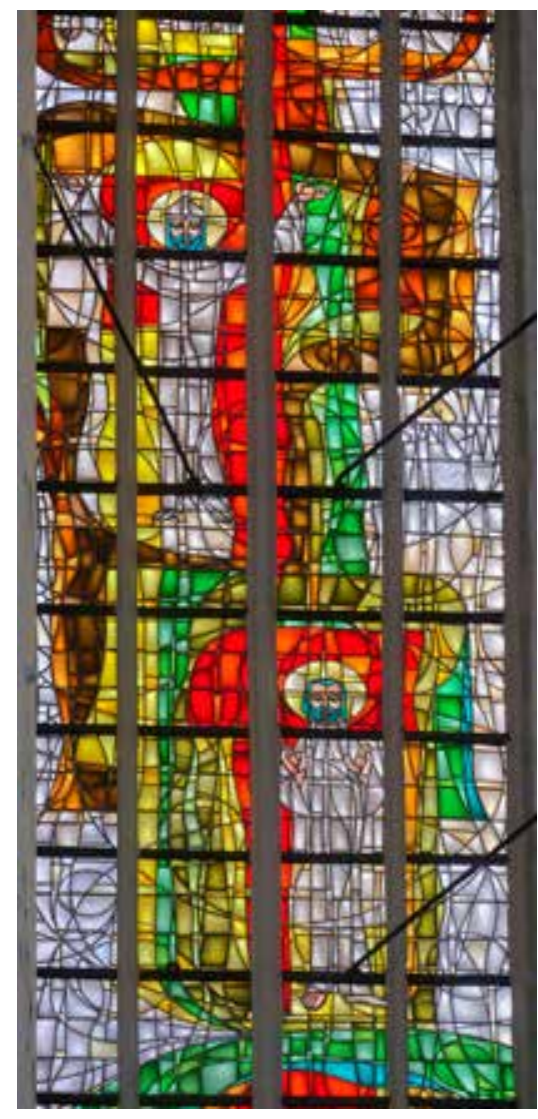

Il. 6. Św. Stanisław i św. Jan Sarkander, fragment witraża w kaplicy Kapłańskiej kościoła Mariackiego w Gdańsku, proj. Wiktor Ostrzołek, 1978, fot. Dariusz Kula Images
Dla niniejszych rozważań ta grupa przedstawień jest mniej istotna $-\mathrm{z}$ wyjątkiem wizerunku Bazyliki św. Piotra (il. 9). Pożądany sens teologiczny można było przekazać, posługując się dowolnym wizerunkiem kościelnego budynku. Odwołanie do ogólnego wyobrażenia sakralnej budowli bez ukazywania konkretnego obiektu byłoby tu chyba nawet bardziej zrozumiałe ze względu na uogólniony charakter pozostałych obrazów tej grupy. Tymczasem zdecydowano się na przywołanie ściśle określonej świątyni. Konkretyzacja ta domaga się objaśnienia i sądzę, że przynosi je odwołanie do stosunkowo wówczas niedawnych wydarzeń milenijnych. W okresie, gdy ks. Zator-Przytocki zlecał Ostrzołkowi przygotowanie projektów i gdy podejmowano decyzje co do ich ikonograficznego przekazu, echo milenijnych obchodów musiało być wciąż żywe, zwłaszcza $\mathrm{w}$ wypadku tak aktywnie $\mathrm{w}$ nie zaangażowanego proboszcza Bazyliki Mariackiej. Jeśli przypomnieć sobie silnie antywatykański charakter polityki i propagandy komunistycznej w trakcie obchodów Milenium $^{23}$, można domyślać się w wyborze tego szczególnego motywu architektonicznego deklaracji wierności Rzymowi, przy czym biorąc pod uwagę, że projekt witraża powstawał w roku 1978, a śmierć ks. Zator-Przytockiego nastąpiła w końcu listopada tegoż roku, nie można wykluczyć, że zleceniodawca i artysta zdążyli jeszcze zamysł dzieła połączyć z nieoczekiwanym wyborem Karola Wojtyły na papieża, dokonanym w październiku. Przeciwko temu przypuszczeniu przemawia jednak fakt, że wizerunku kardynała Wojtyły brak wśród postaci ukazanych w scenie ślubów jasnogórskich - a więc jednej z trzech scen tworzących drugą grupę omawianych przedstawień.

To właśnie w tych wyobrażeniach najsilniej manifestuje się związek mariackiego witraża $\mathrm{z}$ ideą milenijną. Obrazują one bowiem kluczowe wydarzenia wiążące dzieje Polski z Kościołem rzymskokatolickim. W tym kontekście zupełnie oczywiste jest pierwsze z przedstawień, obrazujące Chrzest Polski (il. 10). Głównym motywem kompozycji jest biskup z pastorałem w dłoni udzielający

23 Zablokowanie planowanej w związku z milenijnymi obchodami wizyty papieża Pawła VI w Polsce stanowiło dobitny wyraz owej antywatykańskiej polityki władz komunistycznych. Na ten temat zob. m.in. Noszczak, „Sacrum” czy „profanum”?..., s. 239-247. 


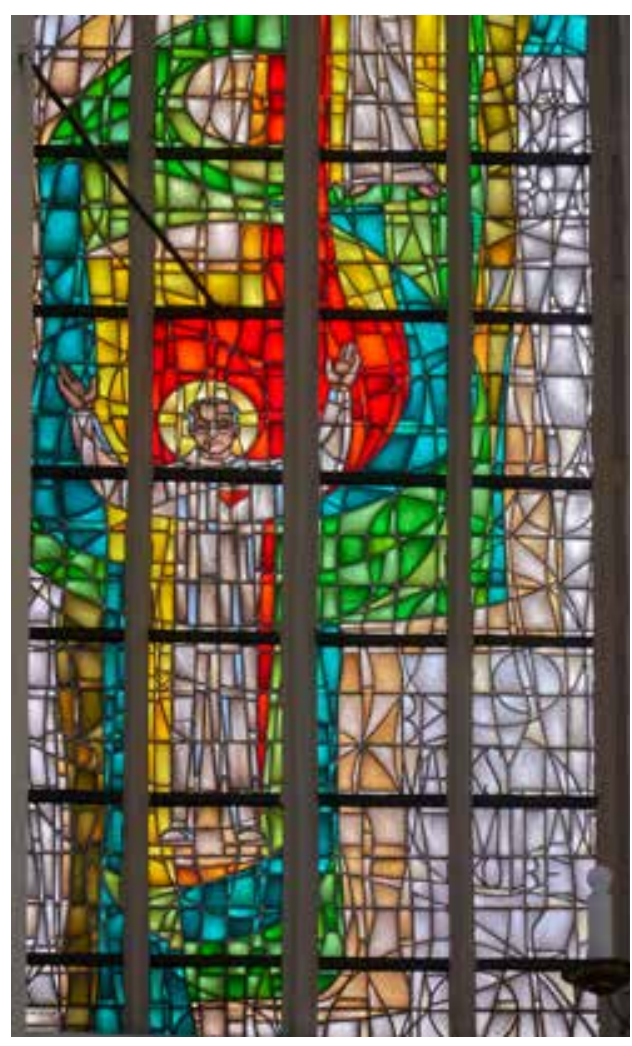

Il. 7. Maksymilian Kolbe, fragment witraża w kaplicy Kapłańskiej kościoła Mariackiego w Gdańsku, proj. Wiktor Ostrzołek, 1978, fot. Dariusz Kula Images

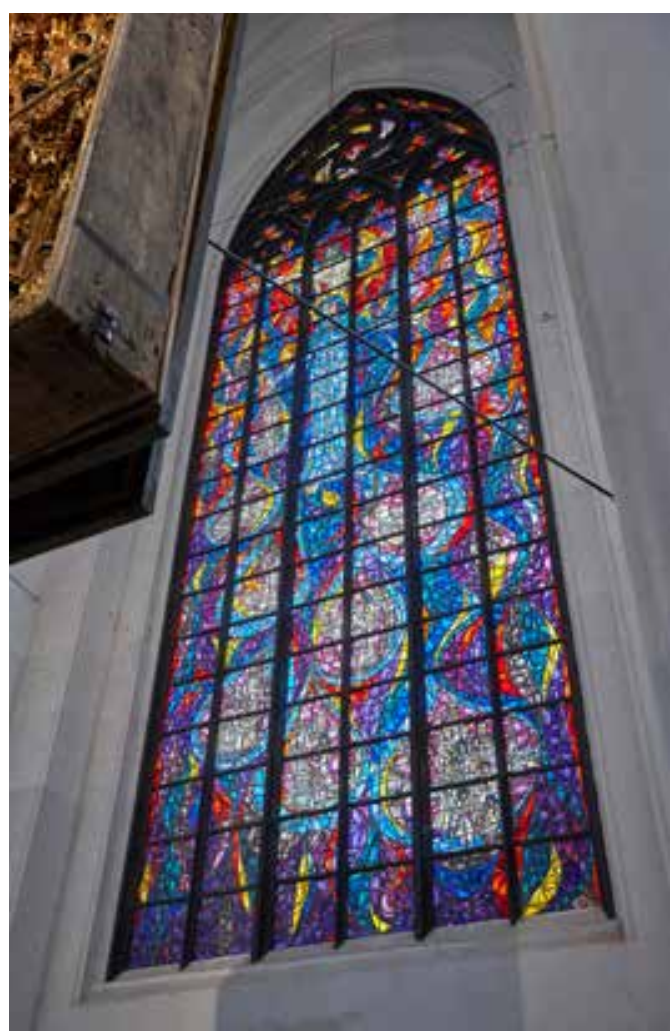

Il. 8. Witraż w prezbiterium kościoła Mariackiego w Gdańsku, proj. Wiktor Ostrzołek, 1980, fot. Dariusz Kula Images

chrztu klęczącemu Mieszkowi, któremu towarzyszy klęcząca Dąbrówka. Drugie $\mathrm{z}$ omawianych przedstawień ukazuje śluby lwowskie Jana Kazimierza (il. 11), składane w obecności biskupa stojącego przy klęczącym monarsze; miejsce złożenia owych ślubów przypomina ukazana w tle sylweta lwowskiej katedry. Trzecia scena przywołuje znów bezpośrednio wydarzenia Milenium, a mianowicie złożone wówczas śluby jasnogórskie ${ }^{24}$ (il. 12). I tym razem miejsce ślubowania zostało ściśle określone za pomocą stosownego motywu architektonicznego, którym jest tym wypadku klasztor paulinów na Jasnej Górze. Tak jak w dwóch sąsiednich przedstawieniach, także tutaj wyraźny jest motyw biskupa z pastorałem, przy czym w scenie ślubów jasnogórskich ukazano konkretne, współczesne osoby duchowne: prymasa Stefana Wyszyńskiego, biskupa gdańskiego Lecha Kaczmarka, biskupa sufragana gdańskiego Kazimierza Kluza, kanclerza kurii

24 Taką identyfikację sceny podaje Bogdanowicz, Dzieła sztuki sakralnej..., s. 281. O tym, że należy ją uściślić, próbuję przekonywać w dalszej części artykułu. 


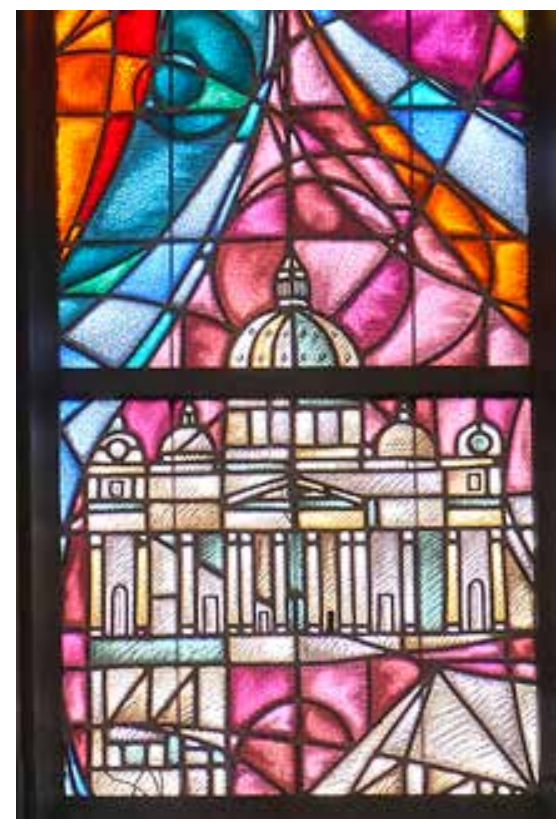

Il. 9. Bazylika św. Piotra, fragment witraża w prezbiterium kościoła Mariackiego w Gdańsku, proj. Wiktor Ostrzołek 1980, fot. Dariusz Kula Images

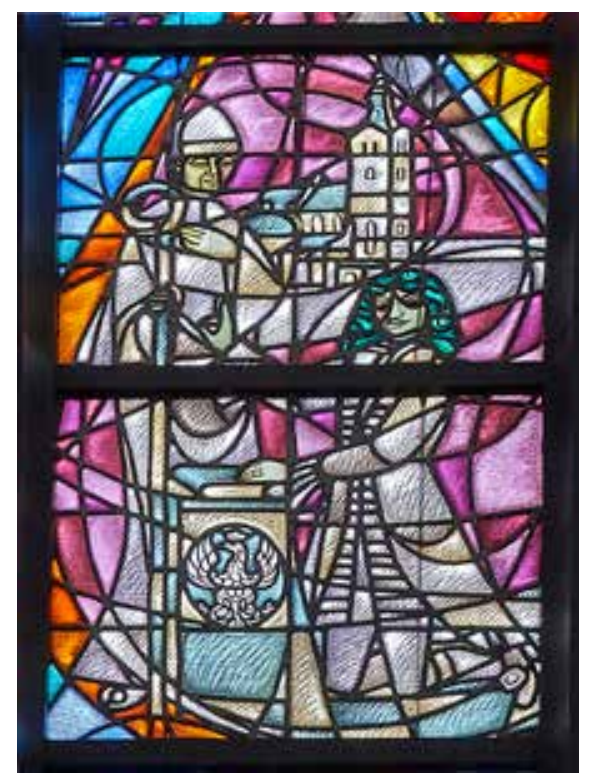

Il. 11. Śluby Jana Kazimierza, fragment witraża w prezbiterium kościoła Mariackiego w Gdańsku, proj. Wiktor Ostrzołek 1980, fot. Dariusz Kula Images

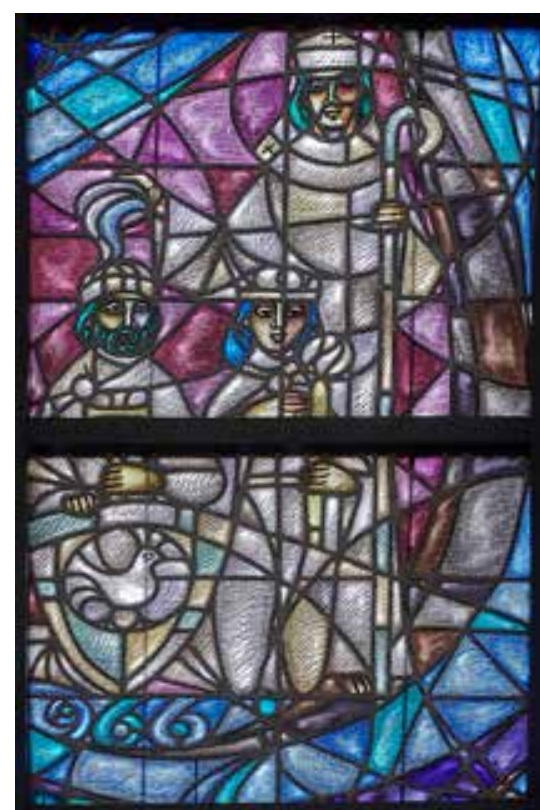

Il. 10. Chrzest polski, fragment witraża w prezbiterium kościoła Mariackiego w Gdańsku, proj. Wiktor Ostrzołek, 1980, fot. Dariusz Kula Images

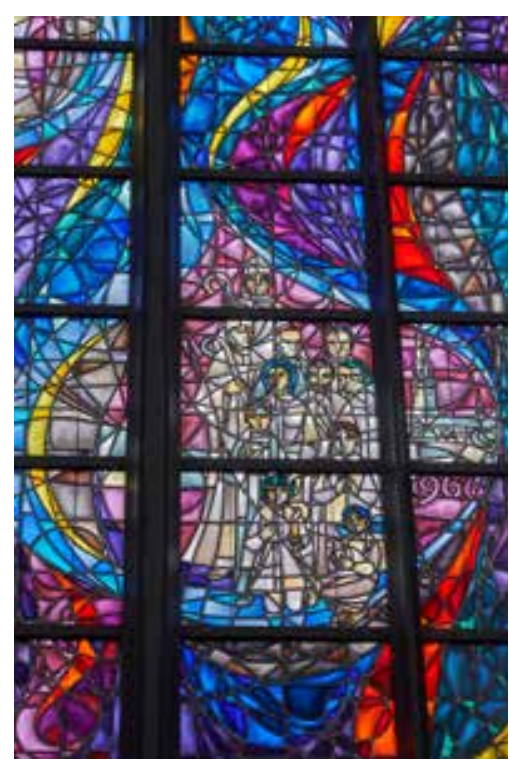

Il. 12. Śluby jasnogórskie, fragment witraża w prezbiterium kościoła Mariackiego w Gdańsku, proj. Wiktor Ostrzołek 1980, fot. Dariusz Kula Images 
gdańskiej, ks. Wiesława Lauera, a także zleceniodawcę i autora witraża, a więc ks. Zator-Przytockiego oraz Wiktora Ostrzołka ${ }^{25}$. Sceny dopełniają wyobrażenia młodych ludzi uczestniczących w historycznym wydarzeniu. Identyfikację przedstawień potwierdza wkomponowana w każdą z nich data, kolejno: „966”, „1656” oraz „1966”.

Wybór tych scen został bez wątpienia głęboko przemyślany. Nie są to ani najważniejsze wydarzenia $\mathrm{z}$ dziejów Polski, ani też przedstawienia cierpień czy klęsk narodowych, choć sam autor witraża wskazywał, że polska historia przesiąknięta jest łzami, a swoiste, kroplopodobne formy, w które ujęte zostały poszczególne sceny, nazwał „łzami Matki Bożej”26. Co więcej, nie są to nawet najważniejsze momenty z dziejów Kościoła w Polsce, ale akty zawierzenia Polski Bogu i Marii. Pierwszym, inicjalnym jest oczywiście Chrzest Polski; drugim - śluby lwowskie z 1656 r.; ostatnim, podsumowującym tysiącletnią historię - akt ślubów jasnogórskich złożonych w roku 1956, w trzechsetną rocznicę ślubów Jana Kazimierza, a równocześnie dziesięć lat przed wielkim jubileuszem tysiąclecia chrześcijaństwa w Polsce. Jak wiadomo, śluby jasnogórskie zostały odczytane pod nieobecność prymasa Wyszyńskiego, więzionego wówczas przez komunistów. Na gdańskim witrażu postać prymasa jednak się pojawia, co w połączeniu z datą "1966” należy odczytać jako wskazówkę, że nie chodzi tu o konkretną historyczną scenę, ale o cały, zainicjowany w 1957 r., proces Wielkiej Nowenny, którego zapowiedzią były złożone rok wcześniej śluby jasnogórskie, a kulminację stanowiły właśnie obchody Milenium.

W tym świetle przedstawienie Marii, jak to czyni monografista witrażowej twórczości Ostrzołka - Henryk Pyka ${ }^{27}$, można niewątpliwie odczytać jako wizerunek Matki Kościoła, zwłaszcza w kontekście opiekuńczego gestu, którym Matka Zbawiciela otacza poszczególne sceny o eklezjologicznej wymowie. Równocześnie można jednak uznać gdańską wizję za wyobrażenie Marii jako nie tylko Matki Kościoła Powszechnego, lecz także bardziej specyficznie - jako Matki Kościoła Polskiego. Biorąc pod uwagę milenijne konotacje omawianego dzieła i zdecydowanie maryjny wydźwięk kościelnych obchodów milenijnych, świadome wykreowanie tego rodzaju przekazu przez ks. Zator-Przytockiego i Ostrzołka jest wielce prawdopodobne. Oczywiście należy również pamiętać o maryjnym wezwaniu samego kościoła. W tym wypadku jednak odwołanie do Marii jako patronki gdańskiej świątyni i opiekunki Kościoła, w tym Kościoła w Polsce, w żaden sposób się nie kłócą, a przeciwnie - znakomicie dopełniają.

Podsumowując, można więc wysunąć przypuszczenie, że oba witraże zrealizowane w końcu lat siedemdziesiątych XX w. w gdańskim kościele Mariackim stanowią pod względem ikonograficznym kontynuację działań podjętych w tej świątyni w okresie milenijnym, zgodnych z nadrzędnym przekazem kościelnych

Identyfikację postaci podaje Bogdanowicz, Dzieła sztuki sakralnej..., s. 281.

Cyt. za: Pyka, Witraże Wiktora Ostrzołka..., s. 75.

Ibidem, kat. nr 36. 
Jacek obchodów tysiąclecia Chrztu Polski, w którym wątki religijne splatały się z wątFriedrich kami historycznymi i patriotycznymi, wskazując tym samym, że historia Polski jest nieodłączna od historii chrześcijaństwa w Polsce.

\section{Bibliografia}

Bielak Jacek, Nowoczesność w strefie sacrum. Dekoracje milenijne w kościele Mariackim w Gdańsku [w:] Nowoczesność w sztuce i w myśli o sztuce na Pomorzu od XIX do XXI wieku, red. Jacek Bielak, Józef Tarnowski, Gdańsk 2015, s. 219-251. Bielak Jacek, Von der „Priester-Kapelle” bis zur „Kapelle der Seeleute”. Die maritime Identität Danzigs am Beispiel der Innenausstattung der Danziger Marienkirche [w:] Die Maritime Stadt - Hafenstädte an der Ostsee vom Mittelalter bis in die Gegenwart. Beiträge der 21. Tagung des Arbeitskreises deutscher und polnischer Kunsthistoriker und Denkmalpfleger in Gdańsk 18-21 September 2013 / Miasto nad morzem - miasta portowe nad Bałtykiem od średniowiecza do wspótczesności. Materiały 21 konferencji Grupy Roboczej Polskich i Niemieckich Historyków Sztuki i Konserwatorów Zabytków w Gdańsku 18-21 września 2013, red. Tomasz Torbus, Katarzyna Anna Wojtczak, Warszawa 2017, s. 474-486.

Bogdanowicz Stanisław, Dzieła sztuki sakralnej Bazyliki Mariackiej w Gdańsku, Gdańsk 1990.

Gucewicz Daniel, Próba sit? Rok 1966 w Gdańsku. Milenium kontra Tysiąclecie, Gdańsk 2014.

Hałagida Igor, Pomorze Gdańskie [w:] Milenium czy Tysiąclecie, red. Bartłomiej Noszczak, Warszawa [2006], s. 237-251.

Lincer Katarzyna, Malarstwo monumentalne w twórczości Barbary Massalskiej na terenie Trójmiasta, Gdańsk 2014 (praca licencjacka napisana w Instytucie Historii Sztuki UG pod kierunkiem Jacka Friedricha).

Noszczak Bartłomiej, „Sacrum” czy „profanum”? - spór o istotę obchodów Milenium polskiego (1949-1966), Warszawa 2002.

Pyka Henryk, Witraże Wiktora Ostrzołka. Pięćdziesiąt lat twórczości, Katowice 2006.

\section{Millennial Echoes in the Iconography of the Stained Glass Windows from 1977-1980 in Gdansk's Church of St Mary}

In 1966, a commemorative decoration appeared inside St Mary's Church in Gdansk: its main component was the painting showing Poland's Baptism placed in the chancel. Meanwhile, a pillar by the Priests' Chapel was decorated with a standard bearing striped concentration camp uniform cloth with numbers of priests-prisoners in Nazi camps. This referred directly to the décor of the Priests' Chapel created not long before, and in which Polish priests murdered during WW II had been commemorated in 1965. Thus the millennial decoration of the chancel clearly associated the history of the Polish state with the history of Christianity in Poland, while the decoration of the Priests' Chapel emphasized the martyrology of Polish priests. Both motifs were clearly continued in two large-size 
stained glass windows installed in the church in the late 1970s: one of them fills in the Ikonografia window in the Priests' Chapel, while the other is to be found in the window closing the church's chancel. Both were designed by Wiktor Ostrzołek, a leading stained glass designer in post-WW II Poland.

The iconographic programme of the first refers to the martyrology of priests, yet it does not limit itself to priests-martyrs in recent history, but shows those connected with it from the very beginning: St Adalbert, Five Martyr Brothers, St Stanislaus, St John Sarkander, St Andrew Bobola and Maximilian Kolbe. Respective figures are interconnected with the use of a clear red line serving as a metaphor of the martyrs' blood. Its continuity connecting St Adalbert with St Maximilian, thus the beginnings of the Polish state with the present, at the same time shows the continuity of the presence of the Catholic Church in Polish history.

This continuity is even more unequivocally expressed by the iconographic programme of the chancel stained glass. Here it is the figure of Mary that stands out; she enshrouds the presentations referring to the Church's mission, and in particular to the Church's mission in Poland, in her protective mantle. A deep interconnection between the history of Poland and the Roman Catholic Church was presented in the three acts of entrusting Poland to God and Mary: the Baptism of Poland in 966, the Lvov Oath of John Casimir in 1656, and the Jasna Góra Pledge connected directly with the 1966 millennial celebrations. 